Open Access

\title{
Transparency systems: do businesses in North Rhine-Westphalia (Germany) regret the cancellation of the Smiley scheme?
}

\author{
Anica Veronika Fietz ${ }^{*}$ and Sven Grüner
}

\author{
* Correspondence: \\ anica.fietz@landw.uni-halle.de \\ Martin Luther University \\ Halle-Wittenberg, Halle (Saale), \\ Germany
}

\begin{abstract}
Our paper explores how participants of voluntary transparency systems react to the cancellation of such programmes. We concern ourselves with participants of the voluntary transparency scheme known as the "North Rhine-Westphalia Smiley". The Smiley system, which awarded the compliant behavior of businesses that joined it, was established in 2007 but cancelled in 2013 due to lack of participants. In our survey, the vast majority of the respondents express regret at the cancellation of the scheme. The goals of this paper are to (i) econometrically explain how sociodemographic, monetary, and non-monetary determinants influence participants' willingness to continue with the voluntary transparency system and (ii) find reasons for the inconsistency between the lack of participants and the expression of regret within our survey. We find evidence that the non-monetary variables "revenue" and "award" and the monetary variable "revenue" influence participants' regret. We speculate that status quo bias and loss aversion are the reasons why businesses favour maintaining the Smiley scheme once they have experienced it.
\end{abstract}

Keywords: Transparency system, NRW Smiley, Behavioural economics, Status quo bias, Loss aversion

\section{Background}

Transparency systems, which publish information on the inspection results of food authorities, are increasingly used to reduce information asymmetries between producers and consumers. Transparent information helps to reduce market failure and thus increase consumer protection (Akerlof 1970, Beulens et al. 2005). Regulatory systems increase both the benefits of compliant behaviour and the disutility of non-compliance via the provision of additional information to consumers. Worsfold (2006a, 2006b) states that consumers request the publication of food inspection results. Moreover, they take the results of such publications into account when making decisions about where to shop or dine. Transparency systems are in operation around the world. Among them, the Danish "Smiley" system was established in 2001 to improve food business hygiene in Denmark (Nielsen 2006), and the "Dine Safe Toronto" transparency scheme (Thompson et al. 2005) aimed to improve hygiene within food businesses in Canada's largest city. In parts of the USA (e.g. New York City and Los Angeles), grades represent business compliance and thus influence consumers' decisions

(c) The Author(s). 2017 Open Access This article is distributed under the terms of the Creative Commons Attribution 4.0 International License (http://creativecommons.org/licenses/by/4.0/), which permits unrestricted use, distribution, and reproduction in any medium, provided you give appropriate credit to the original author(s) and the source, provide a link to the Creative Commons license, and indicate if changes were made. 
regarding where to eat. However, in her review of several hygiene schemes (e.g. the Scottish Healthy Choices award and the Welsh Food Hygiene scheme), Worsfold (2005) argues that, on the one hand, consumers support award schemes, but on the other hand, she criticizes the low public awareness, which may be due to the low number of award winners.

While all transparency schemes pursue similar objectives, they differ in their implementation and design. The schemes are designed either as mandatory for all businesses or voluntary for the businesses that want to participate (Bavorová and Hirschauer 2012). ${ }^{1}$ Furthermore, they vary in their design, including evaluation criteria, pictograms used, and businesses involved (e.g. whether they are restaurants or other food businesses). Many questions have been tackled in the realm of transparency schemes (e.g. how consumers evaluate the quality of food management practices, van Kleef et al. 2007), but the question of how businesses involved think or feel when a transparency scheme is cancelled has not yet been analyzed in detail. Some business owners may miss the transparency scheme, while others may not even care about it. Isolating determinants that influence people's willingness to join the Smiley scheme is important for policymaking (e.g. promoting the advantages of the transparency scheme). If business owners do care, then transparency schemes may work as an incentive that improves a business's hygiene without causing extra cost for the regulator.

We conducted a study in which we analyzed the behaviour of participants of a voluntary transparency scheme. The scheme was voluntary because mandatory transparency systems are currently virtually impossible to set up in Germany due to legal constraints. If mandatory transparency turns out not to be viable, then voluntary transparency systems may be the next best solution to provide consumers with additional information and thus influence business behaviour. This paper adds value to the literature by analyzing a voluntary transparency system for food businesses (the Smiley system) from the perspective of businesses in the German federal state of North Rhine-Westphalia (NRW). Because the owners decided whether to join the Smiley system or not, the system was linked to an award. Thus, this system went hand in hand with a reward if the consumers paid attention to it, i.e. value reputation as an investment.

The NRW Smiley scheme was established in 2007. Initially, it was restricted to restaurants, but it was later expanded to all food businesses. The scheme was based on the inspection results of local food authorities. To join the scheme, businesses had to enter into a contract with the Ministry for Climate Protection, Environment, Agriculture Conservation, and Consumer Protection of the State of North Rhine-Westphalia, which allowed the ministry to disclose the results of the authorities' inspections. Participation did not cause extra costs for businesses, and under the responsibility of the local authorities, the physical food inspections remained unchanged. In addition to standard inspections, the authorities evaluated the compliance behaviour of the businesses using a list of 18 defined criteria, which were evaluated on a five-point scale ("very good" = 1 to "insufficient" = 5). Businesses awarded with a Smiley were allowed to display it at the business location. The pictogram used is shown in Fig. 1. Furthermore, all food businesses awarded with a Smiley could be found on the ministry's home page (https://www.umwelt.nrw.de). The award period was limited to the time until the next inspection. The North Rhine-Westphalia Smiley was cancelled in 2013 due to a lack of participants. Only 520 food businesses out of approximately 93,000 participated. 


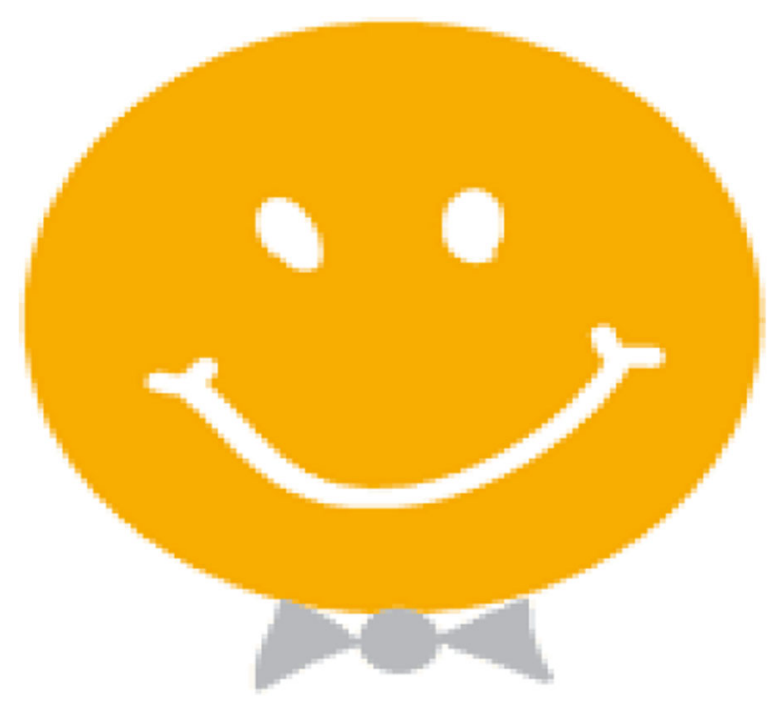

Fig. 1 Smiley pictogram used in North Rhine-Westphalia (Source: Ministry for Climate Protection, Environment, Agriculture Conservation, and Consumer Protection of the State of North Rhine-Westphalia 2007)

In 2014, 1 year after the Smiley was cancelled, we conducted the empirical study that is the subject of this paper.

\section{Research hypotheses}

In this section, we describe the determinants that may influence the extent to which people regret that the Smiley was cancelled and would very much have liked the scheme to have continued. We assume that people are boundedly rational (Simon 1957) and have multiple goals. In the literature, there are several approaches to systematizing multiple goals (e.g. Ostrom 2005, Hirschauer et al. 2012, Nielsen and Parker 2012). Within our analysis, we examine the influence of three categories of variables: (i) socio-demographic (age, gender, and risk attitude), (ii) monetary (competitors and revenue), and (iii) non-monetary (award and conscience) variables. Our hypotheses are summarized in Table 1. Numerous changes in the human body and mind are due to aging, which includes not only outward appearance but also changes of the brain volume (Raz et al. 2005). Even more important for our analysis are people's growing experiences and changing personalities over the course of time (Harris et al. 2016). To overcome limitations such as bounded cognitive abilities, people often rely on

Table 1 Summary of the hypotheses

\begin{tabular}{lll}
\hline Category of variables & Exogenous variables & Influence on $Y$ (regret cancellation of the smiley) \\
\hline Socio-demographic & Age & $?$ \\
& Gender (female) & + \\
Monetary & Risk attitude & + \\
Competitors & + \\
Non-monetary & Revenue & + \\
& Award & + \\
\hline
\end{tabular}


heuristics (Gigerenzer and Gaissmaier 2011). Because we do not know enough about people's experiences, it remains ex ante unclear whether increasing age leads to a higher probability that people regret the cancellation of the Smiley scheme or not.

We are also interested in the differences and similarities between male and female decision-makers. Following Croson and Gneezy's (2009) literature review of economic experiments, we expect differences between women and men. Among others, the literature review shows differences between the sexes in preferences for competitive situations, with men preferring such situations compared to women. Moreover, Croson and Gneezy (2009) find women to be more sensitive to social cues, i.e. greater variability of social preferences than men. We thus assumed women to be more likely to regret the cancelling of the smiley system.

According to Holt and Laury (2002), individual risk aversion increases with a higher monetary stake. Assuming that transparency systems reduce uncertainty, we therefore hypothesized that with an increasing degree of risk aversion, people increasingly regret the cancellation of the Smiley scheme.

People are not purely profit maximizers (Ostrom 2005, Nielsen and Parker 2012), but the material determinants of behaviour are particularly important for businesses that have to ensure their economic survival in a highly competitive market. We assume that the more food businesses suppose that a positive Smiley increases revenue (monetary returns), the more they regret its cancellation.

Another determinant related to a highly competitive market is the number of direct competitors in a business' surroundings. The higher the number of competitors, the greater the challenges for the business. We thus supposed that there was a positive correlation between the number of competitors and people's tendency to regret the cancellation of the Smiley scheme.

The NRW Smiley scheme was a voluntary transparency system that signalled excellent business behaviour to the wider public. Thus, this scheme could be described as an award system that remunerated businesses' compliance.

Awards address important determinants of human behaviour. Starting with Festinger (1950, 1954), the realm of social distinction has been widely studied by social psychologists. Some studies have found that individuals tend to compare their opinions and abilities with those of relevant others (Corcoran et al. 2011). Furthermore, individuals seek to positively distinguish themselves by acquiring status symbols (Frank 1985). Awards also nourish the inherent human desire for social recognition (Frey and Neckermann 2009). We assume that the more food businesses perceive a Smiley as an award for their effort to obey the law, the more they regret the cancellation of such a scheme.

Another non-monetary determinant that has to be taken into account is conscience. Within this variable, we captured the intrinsic motivation of people to obey the law. We think that the more uncomfortable they feel in cases of non-compliance-even if this non-compliance remains undiscovered-the more people regret the Smiley's cancellation.

\section{Data analysis ${ }^{2}$}

We carried out a postal survey using the addresses of all businesses awarded with the Smiley, which were published on the ministry's home page in 2014. In total, 481 
questionnaires were sent out. The businesses were able to use a prepaid envelope; thus, businesses did not incur additional costs by answering our questions. The survey was addressed to the business owners. Our sample consisted of 134 questionnaires, which represented a total response rate of $28 \%$.

\section{Descriptive statistics}

In Table 2, we present the descriptive statistics of both the exogenous variables and the endogenous variable ("Regret cancellation of the Smiley scheme"). On average, those surveyed were 51 years old, male (71\%), and slightly risk seeking. A great variety of competitors of the businesses participated, ranging from 0 to 20 with an average of 4 . Since the variables of revenue, award, and conscience exceeded, on average, 2.0 (on a scale from 0 to 4 ), the subjects agreed with the statements more than they disagreed.

In total, the vast majority of the subjects stated that they regretted that the Smiley scheme was cancelled and would "very much" have liked to continue with it (cf. Fig. 2). We will now econometrically explain this in further detail.

\section{Methods}

The endogenous variable "Regret cancellation of the Smiley scheme" had five possible outcomes and could be ordered according to the degree of agreement of the participants of the survey. Our data did not fulfil the Gauss-Markov assumptions, and thus, the ordinary least squares (OLS) estimator was not BLUE. We relied on Winkelmann and Boes (2006) and many other scholars who propose an ordered logit regression.

Table 2 Descriptive statistics

\begin{tabular}{lllll}
\hline & Mean & Standard deviation & Minimum & Maximum \\
\hline Exogenous variables & & & 29 & 77 \\
Age (in years) & 50.67692 & 8.947058 & 0 & 1 \\
Gender (female) & 29.23077 & - & 0 & 4 \\
Risk attitude $^{\mathrm{a}}$ & 1.191667 & 0.9813028 & 0 & 20 \\
Competitors $^{\mathrm{b}}$ & 3.962963 & 3.766368 & 0 & 4 \\
Revenue $^{c}$ & 2.896825 & 1.041763 & 0 & 4 \\
Award $^{\mathrm{C}}$ & 3.414063 & 0.9181232 & 0 & 4 \\
Conscience $^{\mathrm{e}}$ & 3.073171 & 0.9336227 & & 4 \\
Endogenous variable $^{\text {Regret cancellation of the smiley }}{ }^{\mathrm{f}}$ & 3.293651 & 1.08124 & 0 & 4 \\
\hline
\end{tabular}

af you were to describe your basic risk attitude in business decisions, which of the following statements most likely fit to your attitude? $[0=$ When I make an entrepreneurial decision, the risk does not matter, I only orientate myself on the expected profit. 1 = If I can expect a high profit, I can also live with a great risk. 2 = Even if I can expect a high profit, the risk must be manageable. 3 = Even though I can expect a high profit, the risk must be rather low. $4=$ Even if a high profit is to be expected, I am basically only willing to take a very low risk.]; broadly speaking, i.e. $0=$ highly risk seeking, $1=$ a little risk seeking, 2 = risk neutral, $3=$ a little risk averse, $4=$ highly risk averse

${ }^{b}$ In big cities, the competitive pressure by the large number of resident trades is often described as high. Could you please try to estimate the number of competitors to your businesses in the direct environment? [open question] ${ }^{\mathrm{C}} \mathrm{A}$ positive smiley increases the firm's revenue. [0 = Disagree strongly, $1=$ Disagree a little, $2=$ Neither agree nor disagree, 3 = Agree a little, 4 = Agree strongly]

${ }^{\mathrm{d}}$ The smiley is an award for my effort to obey with all laws. [0 = Disagree strongly, 1 = Disagree a little, 2 = Neither agree nor disagree, 3 = Agree a little, 4 = Agree strongly]

$\mathrm{e}^{\mathrm{e}}$ In case of non-compliance, I always feel uncomfortable even if no one knows about it. [0 = Disagree strongly, $1=$ Disagree a little, 2 = Neither agree nor disagree, 3 = Agree a little, 4 = Agree strongly]

${ }^{f}[0=$ Disagree strongly, $1=$ Disagree a little, $2=$ Neither agree nor disagree, $3=$ Agree a little, $4=$ Agree strongly $]$ 


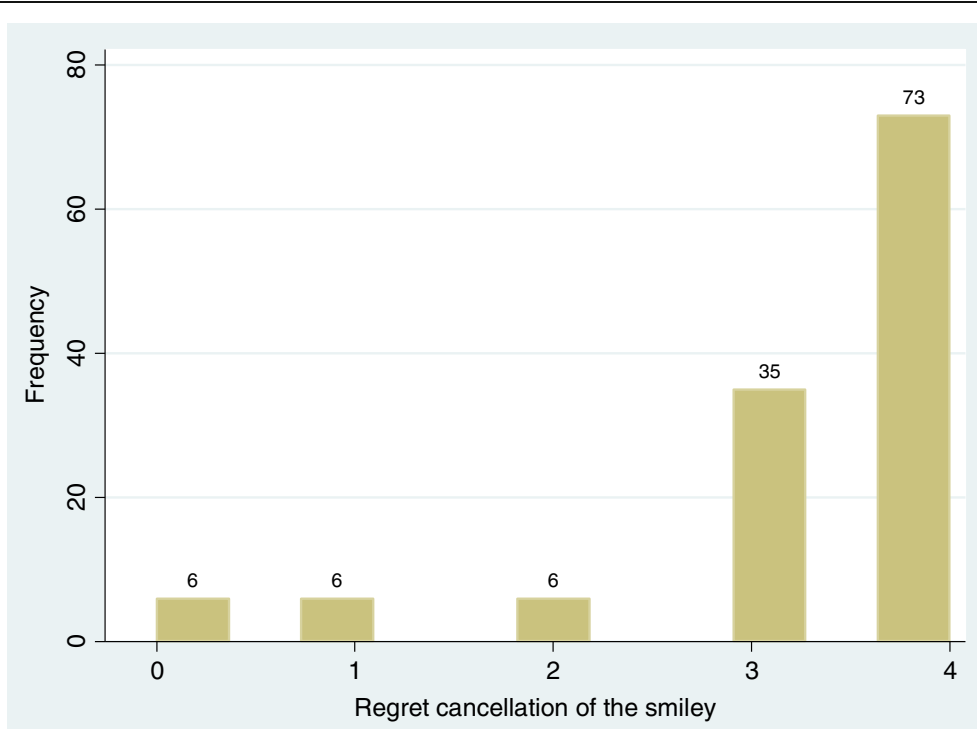

Fig. 2 Fraction of subjects who regret the cancellation of the Smiley scheme (from $0=$ strongly disagree with the statement of regretting to 4 = strongly agreeing with the statement of regretting the cancellation)

Table 3 Results of the ordered logit regression to explain the extent to which businesses regret the cancellation of the Smiley scheme (95 observations)

\begin{tabular}{|c|c|c|c|c|}
\hline Endogenous variable & Coefficient & Standard error & 95\% confidence interval & $p$ value \\
\hline \multicolumn{5}{|l|}{ Exogenous variables } \\
\hline Age & .0149233 & .0262162 & $\begin{array}{l}-.0364595 \\
.066306\end{array}$ & 0.569 \\
\hline Gender (female) & .8247034 & .6349923 & $\begin{array}{l}-.4198587 \\
2.069266\end{array}$ & 0.194 \\
\hline Risk attitude & .2706688 & .2440757 & $\begin{array}{l}-.2077107 \\
.7490483\end{array}$ & 0.267 \\
\hline Competitor & -.0312168 & .0670552 & $\begin{array}{l}-.1626426 \\
.100209\end{array}$ & 0.642 \\
\hline Revenue & 1.135848 & .2735963 & $\begin{array}{l}.5996094 \\
1.672087\end{array}$ & 0.000 \\
\hline Award & 1.224149 & .323259 & $\begin{array}{l}.5905734 \\
1.857726\end{array}$ & 0.000 \\
\hline Conscience & -.7936022 & .3485364 & $\begin{array}{l}-1.476721 \\
-.1104833\end{array}$ & 0.023 \\
\hline /cut1 & .6350166 & 1.752255 & $\begin{array}{l}-2.799341 \\
4.069374\end{array}$ & \\
\hline /cut2 & 2.366019 & 1.681233 & $\begin{array}{l}-.929138 \\
5.661175\end{array}$ & \\
\hline /cut3 & 3.462512 & 1.689228 & $\begin{array}{l}.1516867 \\
6.773338\end{array}$ & \\
\hline /cut4 & 6.003358 & 1.786122 & $\begin{array}{l}2.502622 \\
9.504093\end{array}$ & \\
\hline
\end{tabular}

The null hypothesis of all coefficients being zero in the regression model (except the coefficient of the constant) is rejected by a likelihood ratio test $(p=0.0000)$. Pseudo $R^{2}=0.2705$ 
The results of the regression are depicted in Table 3. The null hypothesis that the regressor $x_{\mathrm{i}}$ has no effect on the endogenous variable can be rejected for the monetary variable of revenue and the non-monetary variables of award and conscience ( $p$ value $\leq 0.05$ ). While revenue and award had the expected positive sign, the variable of conscience had a negative influence, i.e. the more people agreed with the statement that "In case of non-compliance they feel uncomfortable even if no one knows about it", the less likely they were to regret that the Smiley scheme was cancelled. One possible explanation is that those people, who were very intrinsically motivated and had internalized it as a value in itself, were critical towards further steps of regulation. Another possible explanation may be the experiences of the business owners. If they assumed the principle of legality and the general principle of presumption of innocence, they might have assumed transparency schemes to be unnecessary because non-compliance would be sufficiently punished by the legal authorities. The exogenous variables of age, gender, risk attitude, and competitor were not statistically significant $(p$ value $>0.05)$, i.e. the null hypothesis that the regressor $x_{i}$ had no effect on the endogenous variable could not be rejected. Note that it would be an error to conclude that we found any evidence of no effect (cf. Hirschauer et al. 2016, Wasserstein and Lazar 2016). Here, further research is needed for a better understanding of the real influence of these variables on business behaviour. Briefly analyzing the signs, we see that they are in line with our hypotheses with the exception of the variable of competitor, which is, in fact, negative.

Note that since the endogenous variable has five categories, four cut points are estimated, which allows us to compare various levels of the endogenous variable with each other. Due to the small sample size, we do not focus on the cut points. Rather, our aim in this study is to get a first impression of the pooled data.

\section{Results and Discussion}

\section{Results derived from the empirical analysis}

The main aim of this paper was to find reasons why people regret the cancellation of a voluntary transparency system using the example of the NRW Smiley scheme. To adequately discuss our findings, we want to begin by acknowledging the limitations of our study. The sample comprises only 95 subjects. Of probably greater significance is the possible systematic deviation between subjects who joined our survey and those who did not. In other words, self-selection (cf. Rosenthal and Rosnow 1975, Heckman 1979) may bias our findings to an unknown sign and magnitude. That is why we recommend interpreting the findings cautiously.

We found empirical evidence of non-monetary variables and partly monetary variables influencing people's level of regret. However, it is of interest that the Smiley scheme was cancelled because of too few participants, but the vast majority of people who answered our questionnaire wished to continue the Smiley scheme. How can the inconsistency between the low rate of participation in real life versus the high regret rate of cancelling in our questionnaire be explained?

\section{Theoretical explanation}

There may be systematic deviation between people who experienced the Smiley scheme and those who did not. People are boundedly rational. Status quo bias, which may be 
caused by loss aversion, could also increase people's tendency to regret the cancellation of the Smiley scheme. In contrast to the evaluation of final states, changes (relative states) are of considerable importance for human perception. The deviations from a neutral reference point can be encoded as gains and losses. If losses are more strongly psychologically perceived than profits of the same magnitude, then one speaks of loss aversion (cf. Kahneman and Tversky 1984, Kahneman and Tversky 1979, Tversky and Kahneman 1992). Status quo bias describes the tendency to maintain the current state against other options for action (Samuelson and Zeckhauser 1988). Status quo bias can help to explain problems in the policy enforceability of new and more efficient technologies. The individual decision-making behaviour is often not separated from the social context and is instead oriented to social defaults. In practice, it has been shown that a significant difference exists in whether an individual participates in a measure, as long as they explicitly agree (opt-in policy) or do not explicitly reject it (opt-out policy). This observation contradicts the expected utility theory, according to which it should be (almost) irrelevant as to which variant the state implements if one assumes a logical preference ordering. According to Gigerenzer (2010), this behavior can be approximated by using the following heuristic: "If there is a default, do nothing about it".

\section{Conclusion}

In the rest of the paper, we want to surmise possible consequences for policy, society, and research due to the experiences of the NRW Smiley scheme. First, to join the scheme, business owners have to be informed about the existence and details of the transparency system. People are boundedly rational and may ignore information about their relevant environment. Policy may inform people that transparency systems have the potential to distinguish their businesses in spite of revenue and prestige. This might work as a signal that the firms request more information about the Smiley scheme and its implications.

Furthermore, one has to consider that many food businesses are inspected only annually by the authorities. Thus, the food inspectors may not be the first choice to inform the businesses because they have infrequent contact. This is especially true considering that people are confronted with a huge amount of information. To join the Smiley scheme, people probably have to believe that they are good in their business (at least better than some of the relevant others in their environment). Some people may be more optimistic than others. However, for the consumer, it remains unclear whether businesses fail to join the Smiley scheme because they think they are not good enough or because they are uninformed. Thus, it is not easy for the consumers to decide only on the basis of some published results. Note that more people may have joined the Smiley scheme if it had been designed as an opt-out system. They could have gained experience on a willing basis until they decided to leave the scheme. The advantage of this system for society is that consumers receive more information from businesses that are evaluated or actively decide to leave.

The regulator has a sizable variety of measures to take into account when designing a transparency system. First, the regulator has a choice between a mandatory or voluntary system. If the decision is made in favour of a voluntary system, both opt-in and opt-out regimes could be applied. For example, it would be interesting to compare the behavioural influence of mandatory transparency schemes with opt-out schemes. 
Therefore, a comprehensive comparison of these systems that considers the specifics of the countries and business sectors is left open for further academic research.

Furthermore, an interesting question that remains is how businesses evaluate the influence of ratings by private online platforms such as "holidaycheck" or "tripadvisor". Could public transparency be counterbalanced by subjective private ratings and thus be supported by food businesses? Do businesses suffer from inequitable consumer ratings based on personal preferences and tastes? Do these kinds of ratings really influence consumer behaviour as promoted by ubiquitous access to relevant social media and the Internet?

\section{Endnotes}

${ }^{1}$ Bavorová and Hirschauer (2012) stress the distinction between voluntary and mandatory schemes while also providing some insights into the pros and cons of disclosure systems by discussing "Regulation through transparency". Under the title "The Economics of Voluntary Versus Mandatory Labels", Roe et al. (2014) discuss groupspecific welfare effects and political economy aspects.

${ }^{2}$ The data as well as the code of Stata are available on request.

\section{Acknowledgements}

We are very grateful for the support of the DFG (German Research Foundation), which financed this project (Project ID HI 811/5-3). Furthermore, we thank Prof. Dr. Norbert Hirschauer and Dr. Miroslava Bavorova for their support within the project.

\section{Authors' contributions}

AF carried out the empirical study and identified the gap in the literature. There was a close collaboration of both authors, AF and SG, formulating the behavioral research hypotheses, data analysis, and interpreting the findings. All authors read and approved the final manuscript.

\section{Competing interests}

The authors declare that they have no competing interests.

\section{Publisher's Note}

Springer Nature remains neutral with regard to jurisdictional claims in published maps and institutional affiliations.

Received: 21 February 2017 Accepted: 27 October 2017

Published online: 17 November 2017

\section{References}

Akerlof GA (1970) The market for "lemons": quality uncertainty and the market mechanism. Q J Econ 84(3):488-500 Bavorová M, Hirschauer N (2012) Producing compliant business behaviour: disclosure of food inspection results in Denmark and Germany. J Consum Prot Food Safety 7:45-53

Beulens AM, Broens DF, Folstar P, Hofstede J (2005) Food safety and transparency in food chains and networks. Relationships Challenges Food Control 16:481-486

Corcoran K, Crusius J, Mussweiler T (2011) Social comparison: motives, standards, and mechanisms. In: Chadee D (ed) Theories in social psychology. Wiley-Blackwell, Oxford (UK), pp 119-139

Croson R, Gneezy U (2009) Gender differences in preferences. J Econ Lit 47(2):448-474

Festinger L (1950) Informal social communication. Psychol Rev 57(5):271-282

Festinger $L$ (1954) A theory of social comparison processes. Hum Relat 7(2):117-140

Frank RH (1985) Choosing the right pond: human behavior and the quest for status. Oxford University Press, New York

Frey BS, Neckermann S (2009) Awards: a disregarded source of motivation. Rationality Markets Morals 0:177-182 Gigerenzer G (2010) Moral satisficing: rethinking moral behavior as bounded rationality. Top Cogn Sci 2(3):528-554

Gigerenzer G, Gaissmaier W (2011) Heuristic decision making. Annu Rev Psychol 62:451-482

Harris MA, Brett CE, Johnson W, Deary IJ (2016) Personality stability from age 14 to age 77 years. Psychol Aging 31(8): $862-874$

Heckman JJ (1979) Sample selection bias as a specification error. Econometrica 47(1):153-161

Hirschauer N, Bavorová M, Martino G (2012) An analytical framework for a behavioural analysis of non-compliance in food supply chains. Br Food J 114(9):1212-1227

Hirschauer N, Mußhoff O, Grüner S, Frey U, Theesfeld I, Wagner P (2016) Die Interpretation des p-Wertes_-Grundsätzliche Missverständnisse. Jahrbücher für Nationalökonomie und Statistik 236(5):557-575

Holt CA, Laury SK (2002) Risk aversion and incentive effects. Am Econ Rev 92(5):1644-1655

Kahneman D, Tversky A (1979) Prospect theory: an analysis of decision under risk. Econometrica 47(2):263-291 
Kahneman D, Tversky A (1984) Choices, values, and frames. Am Psychol 39(4):341-350

Nielsen A (2006) Contesting competence_change in the Danish food safety system. Appetite 47(2):143-151

Nielsen VL, Parker C (2012) Mixed motives: economic, social, and normative motivations in business compliance. Law Policy 34(4):428-462

Ostrom E (2005) Understanding institutional diversity. Princeton University Press, Princeton

Raz N, Lindenberger U, Rodrigue KM, Kennedy KM, Head D, Williamson A, Dahle C, Gerstorf D, Acker JD (2005) Regional

brain changes in aging healthy adults: general trends, individual differences and modifiers. Cereb Cortex 15(11): 1676-1689

Roe BE, Teisl MF, Deans CR (2014) The economics of voluntary versus mandatory labels. Ann Rev Resour Econ 6:407-427

Rosenthal R, Rosnow RL (1975) The volunteer subject. Wiley, New York

Samuelson W, Zeckhauser R (1988) Status quo bias in decision making. J Risk Uncertain 1:7-59

Simon HA (1957) Models of man. John Wiley \& Sons, New York

Thompson S, de Burger R, Kadri O (2005) The Toronto food inspection and disclosure system: a case study. Br Food J 107(3):140-149

Tversky A, Kahneman D (1992) Advances in prospect theory: cumulative representation of uncertainty. J Risk Uncertain 5(4):297-323

van Kleef E, Houghton JR, Krystallis A, Pfenning U, Rowe G, van der Lans IA, Frewer $\amalg$ (2007) Consumer Evaluation of Food Risk Management Quality in Europe. Risk Anal 27(6):1565-1580

Wasserstein RL, Lazar NA (2016) The ASA's statement on p-values: context, process, and purpose. Am Stat 70(2):129-133

Winkelmann R, Boes S (2006) Analysis of microdata. Springer, Berlin

Worsfold D (2005) Protecting consumers: a review of hygiene award schemes. Br Food J 107(3):162-172

Worsfold D (2006a) Eating out: consumer perceptions of food safety. Int J Environ Health Res 16(3):219-229

Worsfold D (2006b) Consumer information on hygiene inspections of food premises. J Food Serv 17(1):23-31

\section{Submit your manuscript to a SpringerOpen ${ }^{\circ}$ journal and benefit from:}

- Convenient online submission

- Rigorous peer review

- Open access: articles freely available online

High visibility within the field

Retaining the copyright to your article

Submit your next manuscript at $>$ springeropen.com 